\title{
PERBANDINGAN NYALA API TERHADAP NYALA API PADA PELLET MERANTI,MERBAU DAN SONOKELING
}

\author{
M Syeh Amrozhi \\ Teknik Mesin, Fakultas Teknik \\ Universitas Maarif Hasyim Latif, Sidoarjo, Indonesia \\ e-mail : m-syeh-amrozhi@student.umaha.ac.id
}

\begin{abstract}
ABSTRAK
Biomassa merupakan energi alternatif yang dapat menjadi salah satu solusi untuk mengatasi krisis energi di Indonesia. Wood pellet adalah Pengolahan limbah kayu dengan cara menghancurkan limbah kayu menjadi serbuk halus, kemudian dipadatkan dengan mesin press sehingga berbentuk seperti pellet. Wood Pellet berfungsi sebagai energi alternatif ramah lingkungan dengan kadar co2 yang rendah sehingga menghasilkan pembakaran yang sempurna Tujuan dari penelitian ini adalah mengetahui pengaruh temperatur terhadap warna wood pellet biomassa, kemudahan biomassa menyerap moisture content, dan kekerasan dari pellet biomassa yang berasal dari merbau,meranti dan sonokeling serbuk merbau,meranti dan sonokeling merupakan hasil samping dari indutri kayu yang pemanfaatannya masih terbatas. Analisis yang dilakukan untuk mengetahui karakteristik tiap biomassa adalah bentuk wood pellet temperatur dari biomassa,dan warna dari wood pellet,. Semakin tinggi suhu pembakaran mengakibatkan semakin mudah utuk mengetahui warna dan bentuk dari wood pellet. MWood pellet mempunyai temperatur tinggi dengan angka 550 dan mempunyai temperatur terendah pada temperatur $350 \mathrm{C}$
\end{abstract}

Kata kunci: meranti, merbau, sono keling, wood pellet

\section{PENDAHULUAN}

Pada saat ini ketergantungan pemerintah terhadap energi tidak terbarukan sangatlah besar. Pemerintah berupaya mencari sumber-sumber energi alternatif yang dapat diperbaharui, seperti energi biomassa. Biomassa merupakan salah satu diantara energi terbarukanBahan baku pembuatan wood pellet dapat berasal dari limbah industry penggergajian, limbah tebangan dan limbah industri kayu lainnya. Industri baru wood pellet mampu menghasilkan sebesar 40.000 ton sedangkan produksi di dunia mencapai 10 juta ton.

Jumlah ini belum memenuhi kebutuhan dunia pada tahun 2010 yang diperkirakan mencapai 12,7 juta ton. Peluang mengembangkan wood pellet sangat terbuka luas mengingat limbah hasil hutan Indonesia sangat besar Industri penggergajian kayu, disamping menghasilkan kayu gergajian sebagai produk utamanya, juga menghasilkan limbah berupa sebetan, potongan dan serbuk kayu yang rata-rata jumlahnya $40,48 \%$ dari volume dolok dan, terdiri atas sebetan $(22,32 \%)$, potongan kayu $(9,39 \%)$ dan serbuk gergajian (8,77\%) Limbah tersebut belum dimanfaatkan secara optimal oleh masyarakat. Pelet kayu menjadi perhatian utama saat ini karena faktor kemudahan dalam bahan baku dan memiliki karakteristik yang ramah lingkungan. Pelet kayu menghasilkan emisi (NOx, SOx dan HCL) yang lebih rendah dibanding limbah pertanian seperti jerami atau sekam padi.

\section{METODE PENELITIAN}

\section{Tahap preparasi sampel}

Merupakan suatu tahapan penyiapan sampel sedemikian rupa sehingga bahan baku tersebut siap dilakukan proses selanjutnya. Biomassa yang digunakan sebagai bahan baku adalah serbuk meranti,merbau dan sonokeling. Pada tahap ini bahan serbuk meranti merbau dan sonokeling dipress dengan mesin. Kemudian serbuk meranti merbau dan sonokeling dipotong $3 \mathrm{~cm}$.

\section{Tahap Pengujian bentuk nyala api}

Prinsip pengujian ini yaitu mengetahui bentuk dari nyala api yang diperoleh oleh sampel yang dibakar di udara terbuka dengan rentang waktu tertentu.

\section{Tahap pengujian warna nyala api}

Pengujian ini untuk mengetahui warna nyala api yang didapatkan dari hasil pembakaran pellet tersebut dengan bantuan kamera.

\section{Tahap pengujian temperatur nyala api}

Prinsip pengujian ini yaitu untuk mengetahui temperatur yang dihasilkan dari hasil pembakaran yang dilakukan dengan rentang waktu tertentu dengan menggunakan alat bantu kamera dan 
thermokopel,dan didapatkan data dari yang tertinggi sampai terendah.

\section{HASIL DAN PEMBAHASAN}

\section{Analisa Data}

\section{Hasil Pembahasan pengujian}

Pengujian ini dilakukan di tempat ruang kamar dengan keadaan sekitar area aman dan steril dari bahan yang mudah terbakar

a. Bentuk nyala api wood pellet

a) Wood Pellet Meranti

Wood Pelet Meranti dibakar dengan bantuan alat bantu seperti pematik dan minyak Bentuk nyala api dari wood pellet meranti bisa dilihat digambar dibawah ini:

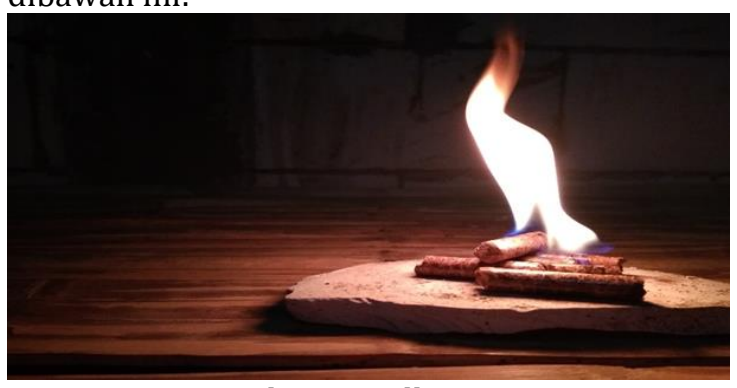

Gambar 1. Pellet meranti

b) Wood Pellet Merbau

Untuk wood pellet merbau pengujiannya sama dengan pengujian dari wood pellet dari hasil pengujian diperoleh hasil dibawah ini :

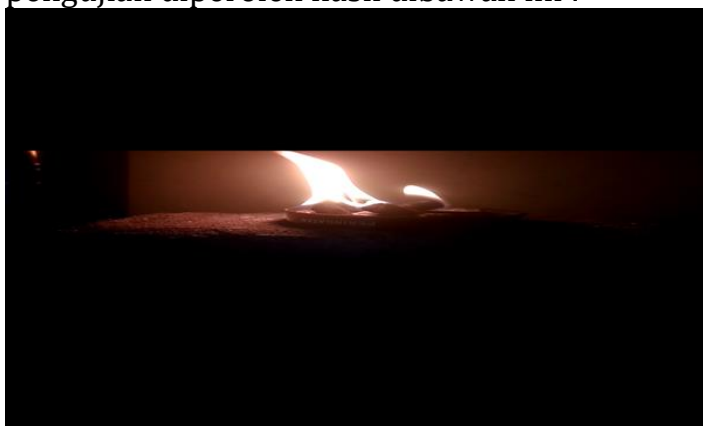

Gambar 2. Pellet merbau

Dari gambar diatas dapat dilihat bentuk nyala api pada pellet merbau yang terbakar dalam ruang kamar.

c) Wood Pellet Sonokeling

Wood pellet sonokeling mempunyai karakteristik yang bagus dan berkualiatas karena dari kayu yang memiliki serat yang bagus dan baik dari itu pasti bagus dijadikan wood pellet seperti hasil pembakaran dibawah ini :

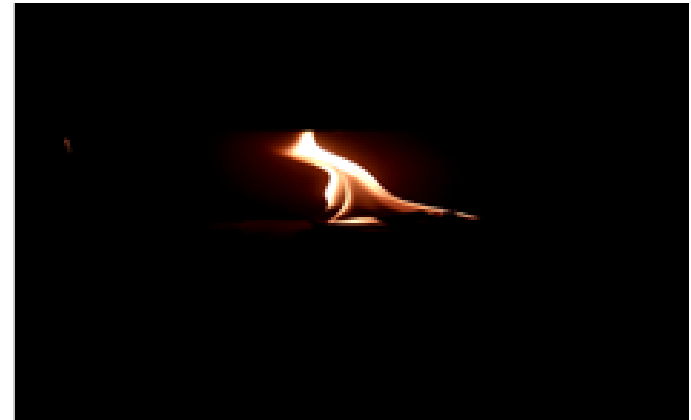

Gambar 3. Bentuk api dari pellet sonokeling

2. Tahap pengujian temperatur nyala api Suhu pellet dapat diketahui dengan membakar pellet dengan menggunakan pellet 500 gram dan mengukur suhu pada saat yang ditentukan dan dibuat kurva antara suhu bara dan waktu seperti grafik digambar 4 dan proses pengambilan data menggunakan alat bantu yaitu thermokopel , kamera dan penggaris

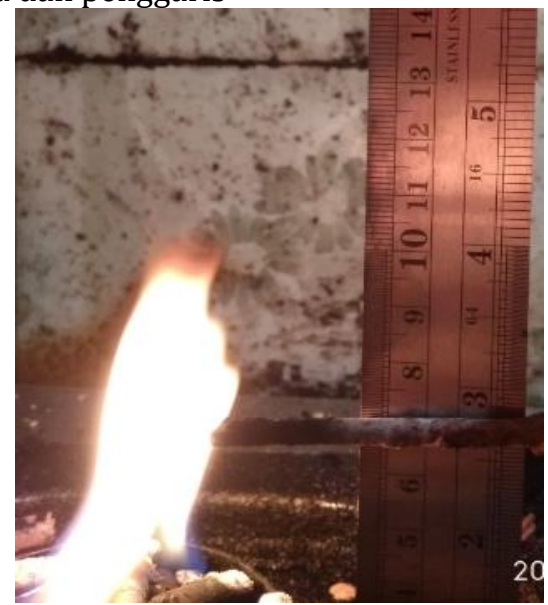

Gambar 4. pada proses pengambilan data

Tabel 1. Temperatur nyala api pada 3 jenis pellet

\begin{tabular}{|l|l|l|l|}
\hline Waktu & Pellet meranti & Pellet merbau & Pellet sonokeling \\
\hline 2 menit & 350 & 400 & 400 \\
\hline 4 menit & 400 & 410 & 420 \\
\hline 6 menit & 450 & 450 & 450 \\
\hline 8 menit & 480 & 500 & 500 \\
\hline 10 menit & 500 & 510 & 550 \\
\hline Rata rata & 436 & 454 & 465 \\
\hline
\end{tabular}

Dari tabel diatas didapat hasil pengujian dengan rentang waktu bervariasi didapat temperatur yang tinggi pada wood pellet sonokeling dengan angka 550 oC dan suhu terendah pada wood pellet meranti dengan suhu 350 oC dan dapat dilihat pada grafik dibawah ini: 


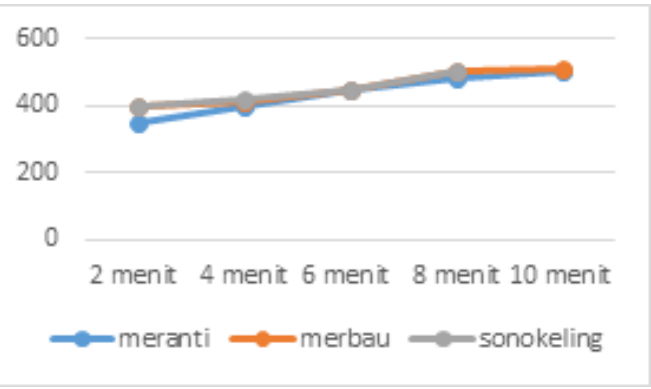

\section{Tahap Pengujian warna nyala api}

\section{a. Wood Pellet Meranti}

Warna nyala api secara umum juga bergantung pada temperatur lihat warna nyala. Api untuk pellet meranti merah tua seperti gambar dibawah ini:

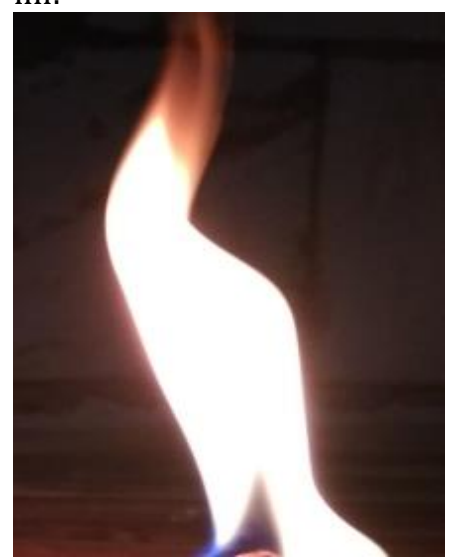

Gambar 6. Warna nyala api wood pellet meranti

b. Wood Pellet Merbau

Warna untuk nyala api wood pellet merbau merah bata terlihat pada gambar dib awah ini:

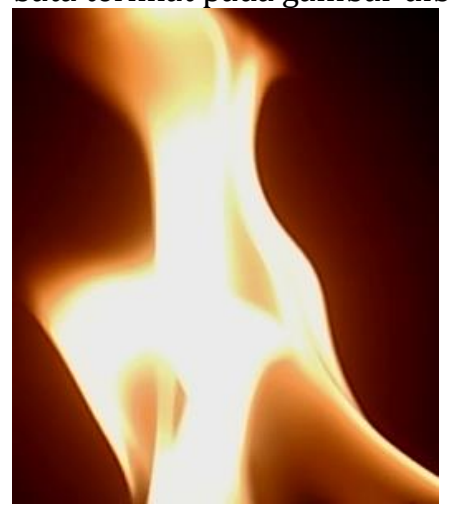

Gambar 7. Warna nyala api wood pellet merbau

c. Wood Pellet Sono Keling

Untuk Warna wood pellet sonokeling coklat jingga seperti gambar dibawah ini.
Gambar 5. Grafik hasil pengujian temperatur pada wood pellet

Dari hasil data diatas, diperoleh suhu bara tertinggi pada wood pellet sono keling dengan suhu bara 550 ${ }^{\circ} \mathrm{C}$ dengan lama membara efektif'adalah 8menit. Dan pada akhir pembakaran briket suhu yang dihasilkan adalah 350 .

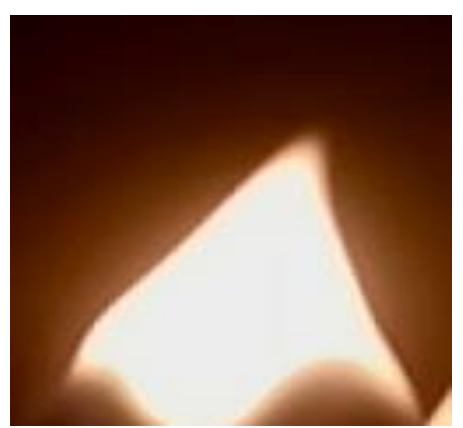

Gambar 8. Warna nyala api wood pellet sonokeling

Dari hasil pengujian diatas diperoleh hasil antara lain bentuk yala api temperatur dan warna nyali api.bentuk nyala api diatas sama karena banyak bercampur dengan oksigen,untuk temperatur berbeda dimna temperatur wood pellet sono keling tinggi dengan jenis wood pellet lainnnya.temperatur yang tinggi berada pada angkan $550 \mathrm{c}$ sedangkan suhu paling rendah berada pada suhu $300 \mathrm{c}$ milik dari wood pellet meranti dan untuk warnanya bermacam macam wood pellet meranti dengan warna merah tua,merbau dengan merah bata dan untuk wood pellet sonokeling warnanya coklat jingga.bisa dilihat ditabel dibawah ini;.

Tabel 1. Hasil Pengujian

\begin{tabular}{|l|l|l|l|l|}
\hline NO & Besaran yang di uji & Pellet meranti & $\begin{array}{l}\text { Pellet } \\
\text { merbau }\end{array}$ & $\begin{array}{l}\text { Pellet } \\
\text { sonokeling }\end{array}$ \\
\hline 1 & Suhu & 436 & 454 & 465 \\
\hline 2 & Lama membara & $\begin{array}{l}6 \text { menit } \quad 1 \\
\text { detik }\end{array}$ & $\begin{array}{l}5 \text { menit } 37 \\
\text { detik }\end{array}$ & $\begin{array}{l}5 \text { menit } 13 \\
\text { detik }\end{array}$ \\
\hline 3 & Asap & Ada & Ada & Ada \\
\hline 4 & Bentuk p & Pejal & pejal & Pejal \\
\hline 5 & Bau & Ada & Ada & Ada \\
\hline 6 & Warna & Merah tua & Merah bata & Coklat \\
\hline
\end{tabular}

\section{PENUTUP}

Dari pelaksanaan kegiatan diperoleh kesimpulan bahwa dalam pengujian pellet, diperlukan perhitungan perencanaan yang matang, agar semua 
dapat bekerja secara maksimal sesuai dengan fungsinya. Simpulan dari pelaksanaan kegiatan ini dapat dijelaskan sebagai berikut

1. Bahwa dari proses pembakaran pellet dapat kita peroleh data yang antara lain warna bentuk dan temperatur api.

2. Hasil dari pengujian tersebut ialah hasil pembakaran dari pellet sonokeling yang bagus dengan nyala api yang stabil dengan temperatur 550 c dan akan tetapi tidak cukup lama dalam bertahan atau lama pembakarannya

3. Dari hasil pengujian diatas dapat diketahui temperatur tinggi mempengaruhi waktu lama pembakaran

4. Warna api juga mengetahui tingkat ketinggian temperatur wood pellet 6. Pasang cdi limiter dan cdi unlimiter

\section{DAFTAR PUSTAKA}

Afifah, Y. N. (2016). Aliran Tak Tunak Fluida Nano Magnetohidrodinamik (MHD) Yang Melewati Bola Teriris.

Afifah, Y. N. (2019). (2019). Analysis of Unsteady Magneto Hydro Dynamic ( MHD ) Nano Fluid Flow Past A Sliced Sphere Analysis of Unsteady Magneto Hydro Dynamic ( MHD ) Nano Fluid Flow Past A Sliced Sphere. IOP Conference Series: Materials Science and Engineering, $\quad 494, \quad 012033$. https://doi.org/10.1088/1757899X/494/1/012033

Afifah, Y. N., \& Putra, B. C. (2018). Model Matematika Aliran Tak Tunak Pada Nano Fluid Melewati Bola Teriris Dengan Pengaruh Medan Magnet. Teknika: Engineering and Sains Journal, 2(2), 119-124.

Gunawan, E., Choifin, M., Khoirul Rosidin, M., Nur Afifah, Y., Lestariningsih, W., Sungging Pradana, M., ... Makki, A. (2019). Analysis of the Effect of Current Flow Variations in GTAW on SS 400 Plate Material Connected with SUS 304 Stainless Steel Plate Against Tensile Strength and Hardness with ER308L Electrodes. Journal of Physics: Conference Series, $1175(1)$ https://doi.org/10.1088/17426596/1175/1/012277

Jatmiko, Riva Suro, Kuntang Winangun, and Muhamad Malyadi. 2019. "PENGARUH PENCAMPURAN BAHAN BAKAR PERTALITE DENGAN BIO ETANOL TERHADAP PEFORMA MESIN INJEKSI YAMAHA VIXION 150CC TAHUN 2011." KOMPUTEK.

Murdianto, I. T. (2019). BAKAR MINYAK KELAPA MURNI TERHADAP SUDUT , PANJANG NYALA. $2,25-32$.
Qomarudin, M. H., Metyana, A. C., \& Afifah, Y. N. (2020). Analisis Kestabilan dan Travelling Wave pada Model Penyebaran Virus Ebola. Briliant: Jurnal Riset Dan Konseptual, 5(2), 369. https://doi.org/10.28926/briliant.v5i2.441

Rozaqi, M. F. (2019). PENGARUH VARIASI DIAMETER LUBANG NOZZLE TERHADAP DIMENSI. 2, 17-24.

Yunita Nur Afifah, MNH Qomarudin, \& Imamatul Ummah. (2020). Optimal Control Model Pemanenan Prey-Predator di Area Konservasi Ikan. Buana Matematika : Jurnal Ilmiah Matematika Dan Pendidikan Matematika, 10(1), 1-16. https://doi.org/10.36456/buanamatematik a.v10i1.2410 